\title{
On regional integration, fiscal income, and GDP per capita *
}

\author{
Yutao HAN $\dagger$ Zhen SONG $\ddagger$
}

August, 2017

\begin{abstract}
This paper investigates the economic impacts of regional integration on a small jurisdiction in a dynamic fiscal competition environment. The tradeoffs between the economic benefits and the loss of policy flexibility resulting from integration are analyzed from the perspectives of fiscal revenue and GDP per capita. Our results show that the small jurisdiction's loss of flexibility in policy making can dominate the other effects of integration. Specifically, if the small jurisdiction's efficiency in providing public inputs is originally sufficiently high (low), regional integration always reduces (improves) its net revenue, independently of the extent of efficiency improvement due to integration. However, when the small jurisdiction's efficiency is originally intermediate, the impact on net revenue crucially depends on the magnitude of the efficiency effect. Our analysis also characterizes the tradeoffs resulting from integration between policy flexibility on the one hand and capital mobility and fiscal equalization on the other.
\end{abstract}

\section{JEL clasification: R12 H87 C73}

Keywords: regional integration; policy flexibility; fiscal revenue; differential game

${ }^{*}$ We would like to thank Jean-François Tremblay for very detailed comments that helped improve the paper, as well as Patrice Pieretti for valuable discussion at the early stage. We also thank the participants of IIPF16 at Reno, CCER Summer Institute17 at Yantai, and seminar at Renmin University of China for helpful comments. Yutao Han gratefully acknowledges the financial support of NSFC (No. 71503044).

${ }^{\dagger}$ Corresponding author: Department of Economics, University of International Business and Economics. 10 Huixindongjie, Chaoyang district, Beijing, China, 100029. Email: yutao.han@uibe.edu.cn or yutao.han2014@gmail.com.

${ }^{\ddagger}$ CEMA, Central University of Finance and Economics, 39 South College Road, Haidian District, Beijing, China, 100081. Email: songzhen@cufe.edu.cn 


\section{Introduction}

Both regional integration and separation have considerably reshaped Europe in the last few decades. The project of European integration, originating in the 1950s, now includes 27 nations. At the same time, some nations have broken up including Yugoslavia, Czechoslovakia and the Soviet Union. The vigorous debate about the economic benefits from regional integration is ongoing. ${ }^{1}$ In the UK for example, membership in the EU has been controversial since the country joined in 1973, and the UK finally left the EU in 2016. Skepticism about the benefits of EU membership is also growing in other parts of Europe while other countries, such as Albania, Serbia and Turkey, have expressed interest in joining the EU.

The general issue of economic integration has attracted much scholarly effort from both empirical and theoretical sides. Henrekson et al. (1997) estimate the economic growth effects from EC/EFTA membership to be about 0.6 to 0.8 percentage point per year. Another recent study by Campos et al. (2014) using the synthetic counterfactuals method finds large, positive effects from EU membership (with the exception of a negative one for Greece). They show that per capita incomes would have been, on average, approximately 12 percent lower without integration. Similarly, Badinger (2005) estimates that the GDP per capita of the EU would be approximately one-fifth lower today if no integration had taken place since 1950 .

On the theoretical side, a political economy literature addresses the benefits and costs of integration. ${ }^{2}$ It mainly focuses on the tradeoff between the economic advantages of unification, which comes from the economies of scale and coordination in public good provision, and the political costs of policies in a unified country that are less close to the preferences of local majorities. ${ }^{3,4}$ In Bolton and Roland (1997), for example, the reasons

\footnotetext{
${ }^{1}$ Regional integration could range from economic to political to environmental, although it has typically taken the form of a political economy initiative where commercial interests are the focus for achieving broader socio-political and security objectives, as defined by national governments.

${ }^{2}$ The theoretical literature distinguishes between economic and political integration and studies their relationship. Casella and Feinstein (2002) and Martin et al. (2012) show that market integration and political integration are complementary. Instead, in Alesina et al. (2000), economic and political integration are substitutes. In this paper, regional integration refers to any forms of economic and political integration that has the impacts we analyze below.

${ }^{3}$ See also Bolton and Roland (1996).

${ }^{4}$ Desmet et al. (2011) quantitatively analyze the stability and breakup of nations and identify the
} 
for integration are that unification may bring about productive efficiency gains and that unification eliminates fiscal competition. In Alesina and Spolaore (1997, 2003), the tradeoff mentioned above endogenously determines the size of jurisdictions. ${ }^{5}$ For comprehensive surveys, see Bolton et al. (1996), Ruta (2005) and Sambanis (2006).

These studies have, however, ignored a cost associated with regional integration, namely the loss of the flexibility in policy making, which we take to mean more responsive decisionmaking in a changing economic environment. Consider, for example, a small jurisdiction that may integrate into a large entity. The large entity could be a country consisting of some regions or a confederation consisting of some member countries. Upon integration, the small jurisdiction may then become a region of the country or a member country of the confederation. We argue that the small jurisdiction will be more flexible in policy making than the large jurisdiction when it stays outside but will suffer a loss in such flexibility upon joining the latter.

First, smallness brings flexibility, in the sense that it permits a jurisdiction to reaction more actively and move quickly to new states of the world. The main reason is that preference heterogeneity in small jurisdictions tends to be lower (Alesina and Spolaore, 2003, pp. 4), which allows them to reach political consensus more easily. Kuznets (1960), Streeten (1993), Armstrong and Read (1995), and Alesina and Spolaore (1997) all recognize that small states have more homogeneous political systems and that this enables them to solve collective decision problems more easily and adapt to changes more quickly and more effectively. Second, because of their smallness, these jurisdictions have less interest groups and can implement legislative and administrative changes more easily. Third, due to the higher openness of many small states, they have to be able to adapt to external changes more quickly and more effectively. Indeed, such states tend to have relatively larger governments that can better help ensure economic security (Rodrik, 1998) and more robust welfare systems that can provide more insurance against international shocks (Katzenstein, 2003).

Second, we expect that joining the large entity will most likely bring losses in policy flexibility to the small jurisdiction. The newly formed entity will adopt some common regions prone to secession and the countries most likely to merge.

${ }^{5}$ Sorens (2005) suggests that larger richer regions with a different language are more likely to support secessionist parties. 
policies in areas such as tax, expenditure, and regulation. Even if the two original entities each retain a significant amount of freedom in setting their own policies, some form of policy coordination or even harmonization will take place. Such coordination and harmonization imply that the small jurisdiction can no longer choose policies independently according to its own wishes, but has to be abided by the restrictions of the coordination/harmonization framework. ${ }^{6}$ For example, tax harmonization can involve coordination among lower level governments, a higher level of government participating in the setting of tax policy of lower levels of government, or revenue sharing. On the expenditure side, harmonization can be accomplished using conditional grants, the spending power of the central government, or mandates imposed on sub-national governments, for example. Even in very decentralized federal countries, subnational jurisdictions will be subject to the influence and restrictions of national norms of efficiency and equity. These may be executive or legislative and may be formal or informal. Recently, legislated fiscal rules that aim at coordinating fiscal policies to achieve good macroeconomic governance have received attention in policy discussions (Boadway and Shah, 2009). This is the case both within some countries and within the European Union. For example, as noted by Alesina et al. (2005), the goal of the EU has been the provision of public goods and common policies for the member states, ${ }^{7}$ which substantially limits their policy independence. In a dynamic modeling framework, such restrictions on policies can lead to a loss of policy-making flexibility - upon integration with the large jurisdiction, the small jurisdiction will not be able to respond to changes in economic environment as quickly as it could before integration. Alesina et al. (2005) studies the cost from the loss of independent policy making upon integration. In the context of our discussion here, such a loss in policy independence may arise from the policy coordination and harmonization discussed above. However, there are major differences between Alesina et al.'s (2005) static concept of policy independence loss and the inherently dynamic concept of flexibility loss that our paper studies. Further explanation of the flexibility concept will be given below in this section, and a comparison between the two concepts will be given in the next section. The loss of policy flexibility has, to the best of our knowledge, not been dealt with before and will be central to our analysis. Essentially, upon joining

\footnotetext{
${ }^{6}$ Ample evidence can be found on the existence of harmonization and coordination in tax and expenditure policies within countries, federal or unitary, and, to a smaller extent, within the European Union. See Boadway and Shah (2009), for example.

${ }^{7}$ It includes a common trade policy, a single internal market, a monetary union, coordinated fiscal policies, and various aspects of domestic policies.
} 
the large jurisdiction, the small jurisdiction understands that in the future it will have to set its policies within the confines of the coordination and harmonization framework. In voluntarily accepting such restrictions, the small jurisdiction essentially commits to constraining all its future policies.

To put the issue of flexibility loss into the regional integration context, we study dynamic fiscal competitions between a small jurisdiction and a large jurisdiction under separation and under integration, respectively. The two jurisdictions are assumed to compete for mobile businesses by using two policy instruments, taxes and public infrastructure expenditures. Each government maximizes its net revenue, defined as the difference between collected tax revenue and public expenditure, by choosing a tax rate applied to capital and a level of public input. Capital is imperfectly mobile across jurisdictions, and public input improves the productivity of private capital. We compare the outcomes in terms of net revenue and GDP per capita under the two regimes in order to analyze the tradeoffs faced by the small jurisdiction between the flexibility loss on the one hand and three impacts of integration that have been studied in the literature on the other hand, namely the changes in public sector efficiency, factor mobility, and fiscal equalization receipts due to integration. These tradeoffs are important in a jurisdiction's decision for whether to integrate with another one. ${ }^{8}$

The dynamic fiscal competition framework we employ is a slightly adapted version of that in Han et al. (2014). The competitions between the two jurisdictions in tax and expenditure policies are modeled as differential games, and the difference in flexibility under the two regimes is reflected in the difference in the strategies that the small jurisdiction can use under each regime. Under separation, the small jurisdiction is more flexible in decision making than its large rival, as we argued above. We formalize this by assuming that the small jurisdiction plays a Markovian strategy (the policy variables can be adjusted in response to the dynamics of the states of the world) while the large jurisdiction plays an open-loop strategy (the policy variables are set only once at the initial time). Under integration, the small jurisdiction's policy flexibility is reduced, and hence we assume that both jurisdictions play open-loop strategies.

This paper and Han et al. (2014) can be seen as twin papers - they use largely the

\footnotetext{
${ }^{8}$ It could be argued, for example, that these tradeoffs could be part of the reasons why Switzerland stays outside the EU and could partially explain the Brexit.
} 
same heterogeneous differential game model that captures the higher flexibility of the small jurisdiction, but they study different issues. Han et al. (2014) study a small jurisdiction's long-run economic prospect when facing dynamic fiscal competition with a large rival. Specifically, they examine the conditions under which the more flexible small jurisdiction's economic size will increase, decrease, or even drop to zero in a steady state of the dynamic fiscal competition game. The two jurisdictions are always separate entities, and regional integration is not considered at all. The present paper goes one step further. We introduce the option of regional integration and study the tradeoffs between the cost of flexibility loss and the potential benefits in public sector efficiency, factor mobility, and redistributive fiscal transfers brought about by integration. Such tradeoffs are new relative to the literature (see Alesina and Spolaore, 1997, 2003). We study how the new tradeoffs impacts the small jurisdiction's incentives to join the large one by comparing its net revenue and GDP per capita under separation with those under integration.

As traditionally studied in the literature, regional integration can have various impacts on an integrating jurisdiction. For simplicity and analytical tractability, we will only focus on the three effects just mentioned, and we study each of them separately. ${ }^{9}$ First, regional integration may increase or decrease the small jurisdiction's efficiency in public good provision. As Bolton and Roland (1997) argue, a unified nation is always more efficient since free trade among regions is guaranteed, duplication costs of defense and law enforcement are avoided and local public good provision can be coordinated. On the other hand, however, Alesina and Ferrara (2005) note that conflict of preferences, racism, and prejudices can often lead to policies that are odious and counterproductive for society as a whole. Hence, integration may also harm the small jurisdiction's public sector efficiency by increasing the heterogeneity of preferences for public goods. Thus, regional integration can improve or reduce the efficiency of public good provision depending on the balance between the two forces above. Second, regional integration facilitates the mobility of factors. ${ }^{10}$ In

\footnotetext{
${ }^{9}$ We do not consider trade effects of integration not because they are unimportant but because they are already well understood. For example, as Alesina et al. (2000) argues that, larger countries experience lower gains from increased openness than smaller countries. The paper argues that trade openness and political separatism go hand in hand: economic integration leads to political disintegration.

${ }^{10}$ Alesina et al. (2000) study how economic integration affects the incentives of countries to integrate or separate (how the degree of openness of the world economy influences political (dis)integration). They suggest that economic integration decreases the benefits of size and induces political disintegration by reducing the cost of international transactions.
} 
the EU, the free movement of goods, persons, services and capital is ensured in accordance with the provisions of the Treaties. One of the most important European achievements linked to the free movement of capital was the introduction of the Euro. Finally, we assume that a fiscal equalization scheme is implemented among the jurisdictions. Many countries have a fiscal equalization system, and to a smaller extent, the EU also uses redistributive fiscal transfers. More discussion and supporting evidence for these impacts of integration will be provided in the model setup section below.

Our main findings can be summarized in relation to the aforementioned tradeoffs between the loss of flexibility and the traditional integration effects. First, efficiency vs. flexibility. If integration reduces the small jurisdiction's efficiency in public input provision, its net revenue and GDP per capita are unambiguously lower than under separation. The other scenario is that integration improves the small jurisdiction's efficiency. We show that integrating into the big entity always reduces (increases, respectively) the small jurisdiction's net revenue if it was relatively efficient (relatively inefficient, respectively) in providing public infrastructure before integration. If the small jurisdiction's efficiency was intermediate, the impacts of integration on net revenue crucially depend on the magnitude of the efficiency gain. GDP per capita increases in the second scenario. Second, fiscal equalization vs. flexibility. If the degree of tax sharing is sufficiently high, integrating into the large jurisdiction improves the small jurisdiction's net revenue. However, and somewhat curiously, regional integration reduces GDP per capita regardless of the degree of tax sharing. Finally, capital mobility vs. flexibility. By enhancing capital mobility, regional integration negatively impacts the small jurisdiction's net revenue and positively impacts its GDP per capita.

Our paper makes two contributions to the literature. First, our paper is perhaps among the first in the study of regional integration to consider the implications of flexibility loss and its tradeoffs with the standard economic impacts of integration, both of which we believe are crucially important for regional integration. Second, existing models on integration and separation are mainly political economy models where strategic interactions among the jurisdictions often do not play a significant role. Our model explicitly uses a dynamic fiscal competition framework where strategic interactions among jurisdictions feature prominently. Besides, although political processes are absent from our model, our framework allows us to simultaneously incorporate a number of important internal 
considerations of benefits and costs, such as the tradeoffs between policy flexibility on the one hand and public sector efficiency, factor mobility, and fiscal equalization on the other hand.

The rest of the paper is organized as follows. The next section reviews the related literature and further clarifies the difference between the concept of independence loss as studied by Alesina et al. (2005) and the concept of flexibility loss that we focus on. Section 3 sets up the model. In section 4, we analyze the steady state of the model. The economic impacts of integration on net revenue and GDP per capita are investigated in section 5 and section 6 , respectively. Section 7 concludes.

\section{Related Literature}

Our paper is related to two strands of literature. First, it is related to the political economy literature on regional integration that was discussed above (Bolton and Roland, 1996, 1997; Alesina and Spolaore, 1997, 2003; Bolton et al., 1996; Ruta, 2005; Alesina et al., 2005). Among them, Alesina et al. (2005) address the loss of independent policy-making by union members. They study how the tradeoff between the benefits of coordination and the loss of independent policymaking endogenously determines the size, composition, and scope of a union. The 'loss of independent policy-making' Alesina et al. (2005) study and the 'loss of flexibility' we consider seem similar, but are in fact different. They compare a rigid union where every member adopts the same policy, as in the standard theory of fiscal federalism (Oates, 1972), with flexible unions where policies can differ across members. We consider dynamic policy flexibility where the small jurisdiction is able to choose its best policy according to the current situation and can therefore adjust to external changes quickly. The policy flexibility in our model is intimately related to the issue of commitment in dynamic games, which determines whether a player can re-optimize based on current conditions and hence, in a differential game context, use a Markovian or an open-loop strategy. Moreover, the concept of policy flexibility does not restrict the players to adopt the same strategy (policy choice), as the concept of policy independence in Alesina et al. (2005) does; in fact, as we shall see below, the two jurisdictions in our model do use different tax and expenditure strategies in equilibrium. These two features distinguish the policy flexibility loss that we study from the loss of policy independence in the literature. 
These being said, we should acknowledge that the two concepts are still related: Part of the reason for the loss of dynamic policy flexibility may stem from the kind of static restriction imposed by the loss of policy independence, such as the tax/expenditure coordination and harmonization discussed in the Introduction. To sum up, the policy flexibility in our dynamic model is not a direct adaptation of the static concept of policy independence into the dynamic context - the two concepts are qualitatively different.

Next, our paper is related to the works where governments compete in both taxes and public inputs that enhance the productivity of capital. Assuming simultaneous tax and expenditure choices, Keen and Marchand (1997) consider a model in which both production public goods and consumption public goods are provided. It is shown that, if production public goods and capital are complements, capital mobility will lead the governments to over-provide production public goods relative to consumption public goods, distorting the composition of public expenditure. Zissimos and Wooders (2008), Hindriks et al. (2008), and Pieretti and Zanaj (2011) consider two-stage models where the governments choose public inputs in the first stage and tax rates in the second. Zissimos and Wooders (2008) show how public input provision can soften tax competition. Tax competition promotes efficiency in their model, and the two governments are ex ante identical. Hindriks et al. (2008) find that equalization discourages public investments but has little effect on equilibrium taxes and that equalization schemes are beneficial for the federation and, under low levels of regional asymmetry, also for the regions. Pieretti and Zanaj (2011) analyze a model where jurisdictions differ in population size and firms face mobility costs. They show that, when the mobility cost is low or moderate, the effective instrument of competition for a jurisdiction is high levels of public input, not low tax rates. Low tax rates can be effective only when mobility cost is high enough. In contrast to these works, our paper employs a differential game framework, where time is continuous and the game lasts forever. This allows us to look at dynamic outcomes that may not be readily seen in static or two-stage games.

Few contributions address dynamic fiscal competition. Wildasin (2003, 2011) and Coates (1993) study tax competition within an explicitly dynamic framework. ${ }^{11}$ Kato

\footnotetext{
${ }^{11}$ Gong and Zou (2002) study the optimal choices of the federal income tax, federal transfers, and local taxes in a dynamic model of capital accumulation and with explicit game structures among multiple private agents, multiple local governments, and the federal government.
} 
(2015) employs a differential game to analyze tax competition in an agglomeration economy. He shows that the commitment of governments to their policies is crucial in determining the distribution of firms in the long run. As discussed in the Introduction, our paper is closely related to the paper by Han et al. (2014), which considers tax and public input competition in a differential game framework. The countries are of unequal population size, and the small country, because of its small size, is more flexible in policy-making than the large country. Their focus is on the long-run outcomes of fiscal competition between independent jurisdictions, which includes the likelihood of collapse of the small jurisdiction. They show that the outcomes depend crucially on the degree of capital mobility. Regional integration is not considered. We borrow the approach of Han et al. (2014) to model the difference in the small jurisdiction's degrees of flexibility under integration and under separation. However, our paper differs from Han et al. (2014) in two aspects. First, instead of just considering the straightforward consequences of fiscal competition as Han et al. (2014) did, in this paper, we introduce the alternative scenario of regional integration and study the new tradeoffs between flexibility loss and other economic impacts of integration for a small jurisdiction, which include the changes in the efficiency of providing public inputs, the entry into a fiscal equalization system, and the changes in capital mobility. Second, our model extends the one of Han et al. (2014) by incorporating efficiency change, factor mobility increase, and fiscal equalization schemes, which substantially complicates the model and its analysis.

\section{The Model}

The basic setting is adapted from Han et al. (2014). The world consists of two jurisdictions, one small and one large. The large jurisdiction can be a union of countries or a country that consists of a number of provinces/states. The small jurisdiction is initially outside the large jurisdiction and may subsequently join the latter to form a new entity. For simplicity and tractability, we do not consider the internal decision process of the large jurisdiction, but just treat it as having a single government that sets all its policies. The world's citizens are all self-employed entrepreneurs, each combining one unit of endowed capital, one unit of inelastically supplied labour, and a local public input to produce output. A jurisdiction's size is equivalent to the size of its entrepreneur population, which is also equal 
to the jurisdiction's capital stock. Hence, labeling the small jurisdiction as jurisdiction 1 and the large one as jurisdiction 2, we may represent their sizes at any time $t$ by their capital stocks, $K_{1}(t)$ and $K_{2}(t)$. We will also use the terms entrepreneurs and their firms interchangeably. We assume that the small jurisdiction will remain small all the time, that is, $K_{1}(t)<K_{2}(t), \forall t \in[0, \infty)$.

Entrepreneurs The total number of the world's entrepreneurs is constant and normalized to unity, so at any time $t$ the world's capital stock is equal to unity, $K_{1}(t)+K_{2}(t)=$ 1. In particular, at time $t=0$, there are $K_{1}(0)$ original entrepreneurs in the small jurisdiction and $K_{2}(0)$ in the large jurisdiction. It is assumed that these entrepreneurs are uniformly distributed on the interval $\left[-K_{1}(0), K_{2}(0)\right]$, which has unit length. Thus, the time-0 border between the two jurisdictions is at the time-0 point of origin, $O$. At any future time, the entrepreneurs are free to migrate to the other jurisdiction. This will change the capital stock in each jurisdiction and hence the location of the border within the unitlength interval. We adopt the convention that the origin point is always placed at the border between the jurisdictions. In other words, migration will shift the origin point $O$ that divides the fixed interval representing the world's total capital stock. Of course, the coordinates of the two ends of the unit interval, $-K_{1}(t)$ and $K_{2}(t)$, will change accordingly.

We assume that migration gives rise to a non-pecuniary disutility cost that has no resource implications. ${ }^{12}$ These costs may reflect cultural and linguistic differences across jurisdictions, for example. To a lesser extent, they may also correspond to the costs for entrepreneurs of adapting to a different legal and regulatory framework, different labour market institutions, tax system, etc. The entrepreneurs are ranked according to this nonpecuniary disutillity cost. Specifically, within each of the subintervals $\left[-K_{1}(0), 0\right]$ and $\left[0, K_{2}(0)\right]$, those with higher costs are farther away from the origin. The instantaneous disutility cost of a migrating entrepreneur is given by $\gamma d(t), t \geq 0$, where $d(t)$ is the distance at time $t$ between the entrepreneur and the initial, time-0 border. Hence, we are assuming for simplicity that all entrepreneurs maintain their initial disutility cost of migration. The coefficient $\gamma$ represents the disutility cost per unit distance of moving capital abroad and can also be interpreted as the degree of international openness.

\footnotetext{
${ }^{12}$ This follows the approach of Boadway et al. (2003) and is different from the original attachment-tohome approach introduced by Mansoorian and Myers (1993), where all individuals, including non-migrants, derive different levels of non-pecuniary satisfaction from residing in their region of residence.
} 
Each firm in jurisdiction $i, i=1,2$, combines own capital $k$ and labour $\ell$ with a local public input $g_{i}$ to produce $F\left(k, \ell, g_{i}\right)$ units of a final good. For tractability, we follow Pieretti and Zanaj (2011) and Han et al. (2014) and assume that the production function takes the simple form $F\left(k, \ell, g_{i}\right)=f(k, \ell)+g_{i}$. Since each firm's capital and labour inputs are fixed, we can denote the part of output contributed by the private inputs, $f(k, \ell)$, by a constant $q$ and simply write a firm's output as $q+g_{i}$. For simplicity, we further assume the cost of private inputs to be constant and equal to zero. Output is sold in a competitive (world) market at a given price normalized to one. Entrepreneurs pay a tax on capital. Given that a common tax rate applies in a jurisdiction and that each entrepreneur invests exactly one unit of capital, all entrepreneurs in jurisdiction $i$ pay the same amount of tax $T_{i}$

The stock of capital of the small jurisdiction that has already moved into the large jurisdiction by time $t$ is given by $K_{1}(0)-K_{1}(t)$. Suppose that, at time $t$, the rate of flow of the small jurisdiction's capital is $x(t)$, with $x(t)>0$ indicating flow from the small jurisdiction to the large jurisdiction and $x(t)<0$ corresponding to flow in the other direction. Then, the distance between the original, time-0 border and the current, time- $t$ border will be $\left[K_{1}(0)-K_{1}(t)\right]+x(t)$. By construction, the marginal entrepreneur of the small jurisdiction who is located at the time- $t$ new border must be just indifferent between investing abroad and staying in the small jurisdiction. Therefore, the following migration equilibrium condition needs to hold: $q+g_{1}(t)-T_{1}(t)=q+g_{2}(t)-T_{2}(t)-\gamma d(t)$, where $d(t)$ is the distance between the marginal entrepreneur, or equivalently the time- $t$ border, and the time- 0 border. ${ }^{13}$ Substituting for $d(t)$ from above yields the following equation for the rate of capital flow

$$
x(t)=\frac{g_{2}(t)-T_{2}(t)}{\gamma}-\frac{g_{1}(t)-T_{1}(t)}{\gamma}+[K(t)-K(0)] .
$$

where, for ease of notation, we have used $K(t)$ in place of $K_{1}(t)$ (so $K_{2}(t)=1-K(t)$ ).

Thus, the rate of capital flow $x(t)$ depends on the difference in the net fiscal benefits in the two jurisdictions, $g_{1}(t)-T_{1}(t)$ and $g_{2}(t)-T_{2}(t)$, adjusted by the disutility cost parameter $\gamma$. The last term, $K(t)-K(0)$, reflects the fact that all entrepreneurs maintain their initial disutility cost of migration.

\footnotetext{
${ }^{13}$ Conversely, if entrepreneurs move from the large jurisdiction to the small jurisdiction $(x(t)<0)$, the migration equilibrium condition becomes $q+g_{1}(t)-T_{1}(t)-\gamma d(t)=q+g_{2}(t)-T_{2}(t)$.
} 
The equation of motion for the small jurisdiction's capital stock $K(t)$ is thus given by

$$
\dot{K}(t)=-x(t) .
$$

The non-pecuniary cost of migration ensures that a migration equilibrium is interior. It precludes complete agglomeration into one jurisdiction which could otherwise occur with linear production functions. The existence of migration costs also allows us to examine the implications of increased mobility due to regional integration. This contrasts with Hindriks et al. (2008) and Zissimos and Wooders (2008), who assume perfect factor mobility and therefore do not consider the impact of changes in mobility costs on the fiscal competition equilibrium.

Governments Each government collects taxes on capital invested in its jurisdiction to finance the production of public inputs and to provide public goods and services to its residents, which may include security, justice, better environment, health care and education. We assume that the taxation process is subject to collection and compliance costs. In particular, government revenues collected from imposing a tax of rate $T_{i}$ on the stock of capital $K_{i}$ are equal to $\sqrt{K_{i} T_{i}}, i=1,2$. Collected tax revenue is assumed to be a concave function of statutory tax payment, and this can arise if the marginal cost of tax collection rises.

The cost of providing public input $g_{i}$ is assumed to be quadratic, $c_{i}\left(g_{i}\right)=\theta_{i} g_{i}^{2} / 2$, $i=1,2$, where $\theta_{i}$ is a jurisdiction-specific efficiency parameter. For simplicity, we normalize $\theta_{2}$ to unity, and, denoting relative efficiency by $\theta$, we have that the small jurisdiction's efficiency is $\theta_{1}=\theta \theta_{2}=\theta$.

We assume that the small jurisdiction is less efficient, that is, $\theta>1$. The larger the value of $\theta$, the less efficient the public sector of the small jurisdiction is relative to that of the large jurisdiction. The most important reason why small jurisdictions are typically less efficient in providing public services and public inputs lies in the economies of scale and coordination in public good provision (see Alesina and Spolaore 1997, 2003, for example).

We will henceforth refer to collected revenues net of the costs of public inputs, $\sqrt{K_{i} T_{i}}-$ $c_{i}\left(g_{i}\right)$, as net government revenues. As mentioned above, this is the amount that can be used to provide public goods and services to residents and can therefore also be seen as an 
approximate measure of the welfare of local residents. For simplicity and tractability, we assume that governments maximize the discounted flow of net revenue, $\int_{0}^{\infty} e^{-r t}\left[\sqrt{K_{i} T_{i}}-\right.$ $\left.c_{i}\left(g_{i}\right)\right] d t .^{14}$

Integration versus Separation The small jurisdiction can choose to stay outside the large jurisdiction (separation) or join it (integration). As discussed in detail in the Introduction, the small jurisdiction will be more flexible in policy making than the large jurisdiction when it stays outside but will suffer a loss in such flexibility upon joining the latter. Besides, integration will also change the efficiency of the public sector, the cost of capital mobility, and the receipts of equalization payment.

The last three impacts have been briefly discussed in the Introduction. Here we provide some more supporting evidence to further motivate our modeling assumptions on these impacts. In what follows, we will denote parameters under integration by upper case letters and those under separation by lower case letters - integration leads to a larger entity. If a parameter only appears under one regime, lower case letter will be used. On the other hand, we will use superscripts $I$ (integration) and $S$ (separation) for endogenous variables.

First, the efficiency of the provision of public infrastructure can be altered by regional integration. Denote the relative efficiency of the small jurisdiction under regional integration by $\Theta$ and that under separation by $\theta$. On the one hand, integrating into the large jurisdiction leads to a higher degree of preference heterogeneity in public goods than that under separation. Integration can lead to a larger number of interest groups and cause more heterogeneity of preferences, conflicts between races, and prejudice. These negative impacts can be translated into a higher cost for a given level of public provision and hence

\footnotetext{
${ }^{14}$ Formally, this is similar to the Leviathan view of governments that has been adopted elsewhere in the tax competition literature (Edwards and Keen, 1996; Wrede, 1996; Keen and Kotsogiannis, 2003 for example), although here governments are assumed to maximize the difference between revenue collection and the cost of public inputs. Alternatively, we could have explicitly considered jurisdictions populated with mobile entrepreneurs and immobile residents who derive benefits from consuming public goods, with governments maximizing the welfare of immobile residents. This would not affect any of our results. Another possible approach would be to assume that the governments maximize some function of individuals' utilities or even simply total production net of the cost of public inputs, reflecting the notion that governments may value the benefits from both private consumption and public goods consumption. However, doing so would not change the strategic incentives of the governments in any important way, and would leave the qualitative nature of our results unaffected.
} 
the inefficiency of the small jurisdiction will be exacerbated. On the other hand, economies of scale in public good provision tends to improve the small jurisdiction's relative efficiency. The scale economies assumption is an assumption that is often adopted in works on the size of nations/unions. ${ }^{15}$ Sandler and Hartley (1995) provide empirical evidence that the per capita cost of certain public goods actually decreases with the population size. Moreover, in the operation of public infrastructure and public utilities, there may be better information sharing and better coordination between the two jurisdictions after integration. The small jurisdiction may also benefit from the experience and technology of the large jurisdiction. All these contribute to increase the relative efficiency of the small jurisdiction. To summarize, if the effect of population heterogeneity dominates the effect of scale economies, we have $\theta<\Theta$; otherwise, we have $\theta>\Theta$. Note that we are capturing the two opposing impacts of integration on efficiency often analyzed in the literature, preference heterogeneity and scale economies, in one efficiency parameter. This allows us to better focus on the new type of cost of integration that our paper introduces, the effect of flexibility loss.

Second, integrating into the large entity can increase the mobility of capital. In the case of a small region becoming part of a country, this seems obvious. As Alesina and Spolaore (2003, p. 83) note, even when trade is free from formal protectionist policies and financial market is liberalized, country borders still matter. The literature on border effects in trade and financial markets provide evidence on this. McCallum (1995) found that trade among Canadian provinces are much larger than that between Canadian provinces and the US. ${ }^{16}$ Portes and Rey (2005) found similar border effects in financial markets. Some recent studies relate the impacts of distance on goods trade and on asset trade and show that barriers to international trade in goods can also reduce bilateral asset holdings (for example, Aviat and Coeurdacier, 2007). In the case of a small jurisdiction joining the EU, under the 'four freedoms' principle, ${ }^{17}$ a common objective of the Member States in

\footnotetext{
${ }^{15}$ In Alesina and Spolaore's (1997) model, for example, each country's government has a fixed cost $k$, so the larger the country's population, the lower each citizen's tax bill will be. As the authors clearly indicate, this captures economies of scale associated with a larger jurisdiction. See also some of the works surveyed by Ruta (2005) and the book by Alesina and Spolaore (2003).

${ }^{16}$ Anderson and van Wincoop (2003) later showed that the border effect found using previous methodology would be too large for small economies, but even when such bias was accounted for, border effect was still significant.

${ }^{17}$ The Treaty on the Functioning of the European Community stipulates that 'The internal market shall comprise an area without internal frontiers in which the free movement of goods, persons, services and
} 
the Single Market is to eliminate any existing obstacles standing in the way of the free movement of persons, goods, services and capital. Hence, denoting the unit relocation cost of capital under integration by $\Gamma$ and that under separation by $\gamma$, we assume $0<\Gamma<\gamma$.

Finally, the small jurisdiction will enter a redistributive intergovernmental fiscal transfer system upon integration with the large jurisdiction. Intergovernmental fiscal transfers, which may be broadly classified into conditional and unconditional transfers, are an important aspect of subnational finance in most countries. They finance about 60 percent of subnational expenditures in developing countries and transitional economies and about a third of such expenditures in the OECD countries. ${ }^{18}$ These transfers serve to jointly balance federal and subnational budgets, to equalize the potential for regions to provide comparable levels of public services at comparable levels of taxes, to achieve other national efficiency and equity objectives such as maintaining national standards of public services and harmonizing policies, and to achieve economic stabilization through risk sharing within countries (Boadway, 2007; von Hagen, 2007). As an important category of intergovernmental fiscal transfers, equalization transfers aim at redistributing revenue from the better-off to the lesswell-off regions. They are used in many countries, including Canada, Germany, the U.S., Denmark, Sweden, Switzerland, and a large number of developing countries (Boadway and Shah, 2009; Bucovetsky and Smart, 2006; Hindriks et al., 2008). In the EU context, the Structural Funds and the Cohesion Fund, together with the Common Agricultural Policy, make up the great bulk of EU funding and the majority of EU spending. The Structural Funds and Cohesion Fund are set up to implement the EU's regional policy. They aim to reduce regional disparities in income, wealth, and opportunities. Even though all regions can be eligible, the poorer regions of the EU receive most of the transfers. Thus, some countries are net contributors, while others are net receivers. The members' contributions are redistributed through such regional policies. Indeed, as Wagner (2006) noted, some of the countries that joined the EU in 2004 'placed great hopes in greater financial aid by the EU, in larger FDI flows and a quicker implementation of the necessary structural reforms'. In this paper, we follow Hindriks et al. (2008) and model the redistributive intergovernmental fiscal transfers under integration by assuming that each region shares a proportion $\alpha$ of its collected tax revenue $\sqrt{K_{i}^{I} T_{i}^{I}}$. We limit $\alpha$ to be in the interval $(0,1 / 2) .{ }^{19}$

capital is ensured in accordance with the provisions of the Treaties.'

${ }^{18}$ Boadway and Shah (2009), page 292.

${ }^{19}$ Real-world equalization systems usually take the size of jurisdictions' population into account, with 
To summarize, regional integration can change the small jurisdiction's public sector efficiency, increase the mobility of capital, and allow it to receive fiscal equalization transfers. Against these potential advantages is the drawback of the loss in policy-making flexibility.

Fiscal Competition Regimes To capture the small jurisdiction's loss of policy flexibility under integration in our differential game framework, we assume that the small jurisdiction plays Markovian strategies when independent and open-loop strategies after it joins the large jurisdiction. An open-loop strategy requires that a player commit to a path of actions calculated at the beginning of the game and not adjust actions according to how state variables evolve. This type of strategy can only be a function time. In contrast, a Markovian strategy allows a player to adjust actions according to the observed values of the state variables as the game evolves. This type of strategy can be a function of both time and the state variables. As for the large jurisdiction, it makes sense to model it as playing open-loop strategies no matter whether the small jurisdiction integrates with it, because it always has a lower level of flexibility in policy making than the small jurisdiction.

Consequently, under separation, the objectives of the small jurisdiction and the large jurisdiction are, respectively,

$$
\begin{gathered}
\max _{g_{1}(t, K), T_{1}(t, K)} \int_{0}^{\infty} e^{-r t}\left[\sqrt{K T_{1}}-\frac{\theta}{2} g_{1}^{2}\right] d t \\
\max _{g_{2}(t), T_{2}(t)} \int_{0}^{\infty} e^{-r t}\left[\sqrt{(1-K) T_{2}}-\frac{1}{2} g_{2}^{2}\right] d t
\end{gathered}
$$

where $r$ is a common discount rate. Both jurisdictions face the constraint

$$
\dot{K}=-x(t) \text {. }
$$

Note that the small jurisdiction's strategy depends on time and the state variable (capital stock), while the large jurisdiction's strategy depends only on time.

Under integration, the objectives of the two governments are, respectively,

$$
\max _{g_{1}(t), T_{1}(t)} \int_{0}^{\infty} e^{-r t}\left[(1-\alpha) \sqrt{K T_{1}}+\alpha \sqrt{(1-K) T_{2}}-\frac{\Theta}{2} g_{1}^{2}\right] d t
$$

the objective of reducing disparities in per capita government revenues or in per capita fiscal capacities. This is the case in Australia, Belgium and Canada, for example. For tractability, however, we assume that equalization transfers are simply proportional to collected tax revenues, although this does not affect the nature of the tradeoffs highlighted by our analysis. 


$$
\max _{g_{2}(t), T_{2}(t)} \int_{0}^{\infty} e^{-r t}\left[(1-\alpha) \sqrt{(1-K) T_{2}}+\alpha \sqrt{K T_{1}}-\frac{1}{2} g_{2}^{2}\right] d t
$$

and both are subject to the constraint

$$
\dot{K}=-x(t)
$$

In this case, both governments play open-loop strategies.

\section{Dynamic Competition}

In this section, we solve the two dynamic fiscal competition games described above, focusing on steady states. The details of derivations are given in an Appendix. Consider the case under separation first.

\subsection{Competition under Separation}

First of all, we consider the separation regime where the small jurisdiction plays Markovian strategy while the large plays open-loop strategy. In steady state, the optimal policies of the two jurisdictions are

$$
\begin{aligned}
g_{1}^{s}=\frac{1}{2 \theta \sqrt{\gamma(r+1)}}, & T_{1}^{s}=\gamma(r+1) K^{s}, \\
g_{2}^{s}=\frac{1}{2 \sqrt{2 \gamma(r+1)}}, & T_{2}^{s}=2 \gamma(r+1)\left(1-K^{s}\right) .
\end{aligned}
$$

The long-run (steady state) capital stock of the small jurisdiction is

$$
K^{s}=\frac{\frac{1}{2 \sqrt{2}}\left(\frac{\sqrt{2}}{\theta}-1\right)}{\gamma^{\frac{3}{2}}(3 r+4)(r+1)^{\frac{1}{2}}}+\frac{2 r+(2+K(0))}{3 r+4},
$$

For the assumption $K^{s}<\frac{1}{2}$ to hold, $\theta$ has to be larger than $\sqrt{2}$. To guarantee that in steady state the net revenue, $\sqrt{K^{s} T_{1}^{s}}-\frac{\theta}{2}\left(g_{1}^{s}\right)^{2}$, is non-negative, we impose the condition $\theta<\widehat{\theta} \equiv r /\left[2 \sqrt{2}(r+1)-8 \gamma^{\frac{3}{2}}(r+1)^{\frac{3}{2}}(2 r+2+K(0))\right]$. Thus, throughout the paper, we assume $\sqrt{2}<\theta<\widehat{\theta}$. 


\subsection{Competition under Integration}

Then we consider the integration regime where both the small and the large jurisdictions play open-loop strategies. In steady state, the optimal policies are

$$
\begin{array}{rlrl}
g_{1}^{I} & =\frac{1}{\Theta} \frac{\sqrt{2 \alpha^{2}-3 \alpha+1}}{2 \sqrt{\Gamma(r+1)}}, & T_{1}^{I}=\frac{\Gamma(r+1)(1-\alpha)}{1-2 \alpha} K^{I}, \\
g_{2}^{I}=\frac{\sqrt{2 \alpha^{2}-3 \alpha+1}}{2 \sqrt{\Gamma(r+1)}}, & T_{2}^{I}=\frac{\Gamma(r+1)(1-\alpha)}{1-2 \alpha}\left(1-K^{I}\right) .
\end{array}
$$

The small jurisdiction's capital stock in the steady state is

$$
K^{I}=\frac{\left(2 \alpha^{2}-3 \alpha+1\right)^{\frac{3}{2}}}{4(\Gamma(r+1))^{\frac{3}{2}}(1-\alpha)^{2}}\left(\frac{1}{\Theta}-1\right)+\frac{1}{2}
$$

To guarantee the non-negativity of the steady state net revenue, $(1-\alpha) \sqrt{K^{I} T_{1}^{I}}$ $+\alpha \sqrt{\left(1-K^{I}\right) T_{2}^{I}}-\frac{\Theta}{2}\left(g_{1}^{I}\right)^{2}$, we assume $\Theta<\widehat{\Theta} \equiv(1-2 \alpha)^{\frac{3}{2}}(1-3 \alpha) /\left[2(1-2 \alpha)^{2}-4 \Gamma^{\frac{3}{2}}(r+\right.$ $1)^{\frac{3}{2}}(1-\alpha)^{\frac{1}{2}}$. Hence, in this paper, we shall always assume that $\sqrt{2}<\Theta<\widehat{\Theta}$.

Now, we are in a position to analyze the impact of regional integration on the small jurisdiction's net revenue. This is taken up in the next section. In light of the continued interest in the effect of EU regional policy on the convergence of member countries' economic performances, ${ }^{20}$ we also compare the levels of GDP per capita of the small jurisdiction under separation and under integration in the section after the next.

\section{$5 \quad$ Net Revenue}

As discussed earlier, regional integration may change the small jurisdiction's public sector efficiency, increase its capital mobility, and allow it to receive equalization transfers. In this section, we will analyze the tradeoffs facing the small jurisdiction between each of these potential advantages of integration and the disadvantage of losing policy-making flexibility. Since analytical derivations that consider all of these potential advantages at the same time seem hard to come by, we will consider each advantage separately, assuming

\footnotetext{
${ }^{20}$ See, for example, Ramajoa et al. (2008), Mohl and Hagen (2010), and Becker, et al. (2010) and the references therein.
} 
away the others or holding them fixed at some exogenous level. Then at the end of the section, we briefly analyze the combined effect.

First of all, we derive the net revenues under integration and under separation. Since in this paper we focus on the impacts of integration on the small jurisdiction, we denote its net revenue $R_{1}(\theta, \gamma)$ by $R(\theta, \gamma)$ to simplify notation. The steady state net revenue of the small jurisdiction under separation is given by

$$
\begin{aligned}
R^{s}(\theta, \gamma) & =\sqrt{K^{s} T_{1}^{s}}-\frac{\theta}{2}\left(g_{1}^{s}\right)^{2} \\
& =\frac{1}{\theta} \frac{r}{8 \gamma(r+1)(3 r+4)}+\frac{1}{\gamma(3 r+4)}\left[\gamma \sqrt{\gamma(r+1)}(2 r+2+K(0))-\frac{1}{2 \sqrt{2}}\right] \\
& \equiv \frac{1}{\theta} \psi_{1}(\gamma)+\psi_{2}(\gamma),
\end{aligned}
$$

where $\psi_{1}(\gamma) / \theta$ represents the first term in the second line and $\psi_{2}(\gamma)$ stands for the second.

The small jurisdiction's steady state net revenue from the dynamic fiscal competition game under integration is given by

$$
\begin{aligned}
R^{I}(\Theta, \Gamma, \alpha) & =(1-\alpha) \sqrt{K^{I} T_{1}^{I}}+\alpha \sqrt{\left(1-K^{I}\right) T_{2}^{I}}-\frac{\Theta}{2}\left(g_{1}^{I}\right)^{2} \\
& =\frac{1}{\Theta} \frac{(1-2 \alpha)(1-3 \alpha)}{8 \Gamma(r+1)}-\frac{(1-2 \alpha)^{2}}{4 \Gamma(r+1)}+\frac{1}{2} \sqrt{\frac{\Gamma(r+1)(1-\alpha)}{1-2 \alpha}} \\
& \equiv \frac{1}{\Theta} \varphi_{1}(\Gamma, \alpha)+\varphi_{2}(\Gamma, \alpha),
\end{aligned}
$$

where $\varphi_{1}(\Gamma, \alpha) / \Theta$ corresponds to the first term in the second line above and $\varphi_{2}(\Gamma, \alpha)$ corresponds to the second and third terms.

Now we compare the impact of integration on net revenues, focusing on the following three tradeoffs: flexibility vs. inefficiency, flexibility vs. capital mobility, and flexibility vs. fiscal equalization.

\section{$5.1 \quad$ Flexibility vs. Inefficiency}

First, we examine the impact of changes in (relative) efficiency ${ }^{21} \theta$ on the small jurisdiction's net revenue $R$. For this purpose, we hold the degree of capital mobility fixed at its

\footnotetext{
${ }^{21} \mathrm{Han}$ et al. (2014) considers how relative efficiency and capital mobility determine the small jurisdiction's economic size at the steady state. However, this is not our focus. We study how the changes in
} 
initial level $\gamma$ and assume away tax sharing by setting $\alpha$ to zero.

The small jurisdiction's steady state net revenue from the dynamic fiscal competition game under integration is given by

$$
R^{I}(\Theta, \gamma, 0)=\frac{1}{\Theta} \varphi_{1}(\gamma, 0)+\varphi_{2}(\gamma, 0)
$$

where $\frac{1}{\Theta} \varphi_{1}(\gamma, 0)=\frac{1}{\Theta} \frac{1}{8 \gamma(r+1)}$ and $\varphi_{2}(\gamma, 0)=\frac{1}{2} \sqrt{\gamma(r+1)}-\frac{1}{4 \gamma(r+1)}$ upon setting $\alpha$ to 0 .

The expression of the steady state net revenue of the small jurisdiction under separation, $R^{s}(\theta, \gamma)=\frac{1}{\theta} \psi_{1}(\gamma)+\psi_{2}(\gamma)$, was given above.

We can distinguish between two situations according to whether integration improves the small jurisdiction's public sector efficiency.

\subsubsection{Efficiency Deteriorates}

The first situation is the simpler one where efficiency falls upon integration. This can be the case if, for example, the negative impact of greater population heterogeneity dominates the efficiency gains from economies of scale. In this case, the cost parameter will satisfy $\Theta>\theta$. In this situation, it can be verified that $R^{s}(\theta, \gamma)>R^{I}(\Theta, \gamma, 0)$ for all permissible values of $\Theta .^{22}$

The intuition is straightforward. The small jurisdiction only incurs two costs and does not enjoy any benefit when joining the large jurisdiction. The first cost is the negative 'efficiency effect'. Joining the large jurisdiction makes it more costly for the small jurisdiction to provide a given level of public input. The second cost is a negative 'flexibility effect': Having to use an open-loop strategy, the small jurisdiction has to commit to a policy path at the beginning of the fiscal competition game and thus loses the flexibility afforded by a Markovian strategy of changing policies according to the capital stock in its jurisdiction. This effect is always negative because, other things being equal, an open-loop strategy allows the small jurisdiction a smaller feasible set in the maximization of its net revenue (its choice variables vary only over space $t$ ) than a Markovian strategy does (its

efficiency (this subsection) and capital mobility (next subsection) resulting from integration interact with the reduced policy flexibility from the fiscal revenue and GDP per capita perspectives.

${ }^{22}$ That is, for all $\Theta \in(\theta, \widehat{\Theta})$, where $\widehat{\Theta}$ is defined in the previous section and is the threshold value of $\Theta$ for a non-negative steady state net revenue. 
choice variables can in principle vary over space $(t, K))$. Since there is no other effect from joining the large jurisdiction, the small jurisdiction's net revenue is necessarily lower than the level under separation.

The results are stated in the following proposition

Proposition 1 Assume that capital mobility is imperfect and that tax revenue is not shared. If integration reduces the small jurisdiction's efficiency in public input provision, its net revenue is unambiguously lower than under separation.

\subsubsection{Efficiency Improves}

Now, we consider the case where integrating into the large jurisdiction improves the efficiency of providing public inputs. That is, the cost parameter is lower under integration than under separation $(\Theta<\theta)$.

The difference between the net revenue under separation, $R^{s}(\theta, \gamma)$, and that under integration, $R^{I}(\Theta, \gamma, 0)$, is given by

$$
\begin{aligned}
& R^{s}(\theta, \gamma)-R^{I}(\Theta, \gamma, 0) \\
= & \frac{1}{\theta} \psi_{1}(\gamma)+\psi_{2}(\gamma)-\frac{1}{\Theta} \varphi_{1}(\gamma, 0)-\varphi_{2}(\gamma, 0)
\end{aligned}
$$

Denoting the root of the equation $R^{s}(\theta, \gamma)-R^{I}(\Theta, \gamma, 0)=0$ by $\Theta^{*}$, we obtain

$$
\Theta^{*}=\frac{\varphi_{1}(\gamma, 0)}{\frac{1}{\theta} \psi_{1}(\gamma)+\psi_{2}(\gamma)-\varphi_{2}(\gamma, 0)} .
$$

Note that $\partial R^{I}(\Theta, \gamma, \alpha) / \partial \Theta<0$ when $\alpha=0$. Thus, we have

$$
R^{s}(\theta, \gamma)-R^{I}(\Theta, \gamma, 0) \gtreqless 0 \text { as } \Theta \gtreqless \Theta^{*}
$$

where $\sqrt{2}<\Theta<\widehat{\Theta}$ as we imposed above.

Three scenarios can be distinguished according to the level of the small jurisdiction's original efficiency (i.e., efficiency under separation). 
Low Efficiency From the definition of $\Theta^{*}$ above, the definition of $\widehat{\Theta}$ at the end of the the last section, and (6), we can see that $\Theta^{*}>\widehat{\Theta}$ when $\theta>\bar{\theta} \equiv \max \{\sqrt{2}$, $\left.\psi_{1}(\gamma) /\left[\varphi_{1}(\gamma, 0) / \widehat{\Theta}-\psi_{2}(\gamma)+\varphi_{2}(\gamma, 0)\right]\right\}$. That is, when the small jurisdiction's cost parameter under separation, $\theta$, is larger than the threshold value $\bar{\theta}$ just defined, the solution to $(6), \Theta^{*}$, will exceed the maximum value permissible in order for the steady-state net revenue to be non-negative, $\widehat{\Theta}$. Since any permissible value of $\Theta$ satisfies $\Theta<\widehat{\Theta}$, we have that $\Theta<\Theta^{*}$ for $\theta>\bar{\theta}$. Then, using (6), we have that $R^{s}(\theta, \gamma)<R^{I}(\Theta, \gamma, 0)$ when $\theta>\bar{\theta}$. In other words, integration improves the net revenue of the small jurisdiction when its original public sector efficiency is worse than that defined by the threshold $\bar{\theta}$, independently of the extent of efficiency improvement.

Again, two effects are at work. The positive 'efficiency effect' lowers the cost of providing a given amount of public inputs. If the small jurisdiction's original efficiency in providing public input is relatively low, the gain from the efficiency effect will exceed the loss from the 'flexibility effect'. In this case, the small jurisdiction's net revenue increases under regional integration.

High Efficiency From (6), we have that the inequality $\Theta^{*}<\sqrt{2}$ holds when $\theta<\underline{\theta}=$ $\min \left\{\widehat{\theta}, \psi_{1}(\gamma) /\left[\varphi_{1}(\gamma, 0) / \sqrt{2}+\varphi_{2}(\gamma, 0)-\psi_{2}(\gamma)\right]\right\}$. Since the permissible values of $\Theta$ always satisfy $\Theta>\sqrt{2}$, we will have $\Theta>\Theta^{*}$ whenever $\theta<\underline{\theta}$. Then, from (6), we know that $R^{s}(\theta, \gamma)>R^{I}(\Theta, \gamma, 0)$ when $\theta<\underline{\theta}$. That is, if the cost of public input provision under separation $\theta$ is lower than the threshold $\underline{\theta}$ defined above, integrating into the large jurisdiction will reduce the net revenue of the small jurisdiction. Again, this occurs regardless of the extent of efficiency improvement. When the small jurisdiction is originally already fairly efficient, the loss from the flexibility effect will exceed the gain from the efficiency effect.

Intermediate Efficiency Finally, when $\theta$ takes an intermediate value, $\underline{\theta}<\theta<\bar{\theta}$, the sign of $R^{s}(\theta, \gamma)-R^{I}(\Theta, \gamma, 0)$ will depend on the relative magnitude of $\Theta$ and $\Theta^{*}$. Depending on parameter values, two cases can emerge. In the first, the efficiency improvement is relatively large, so $\Theta<\Theta^{*}$ holds. From (6), we have $R^{s}(\theta, \gamma)<R^{I}(\Theta, \gamma, 0)$, so net revenue increases. The intuition is straightforward. The positive efficiency effect dominates the negative flexibility effect. The second case is the opposite. Efficiency improvement is relatively low $\left(\Theta>\Theta^{*}\right)$, so the small positive efficiency effect is dominated by the negative 
flexibility effect. Net revenue is thus lower under integration $\left(R^{s}(\theta, \gamma)>R^{I}(\Theta, \gamma, 0)\right)$.

Note that there is an interesting asymmetry in the strength of impact of the flexibility effect across the cases discussed above. When the initial efficiency is intermediate $(\underline{\theta}<$ $\theta<\bar{\theta})$, the net impact on net revenue of the efficiency effect and the flexibility effect is contingent on the extent of efficiency improvement (i.e., on how $\Theta$ compares with $\Theta^{*}$ ). In this sense, the influence of the flexibility effect is mild. However, when the initial efficiency is more extreme $(\theta<\underline{\theta}$ or $\theta>\bar{\theta})$, the impact of the flexibility effect is strong: As long as $\theta$ falls outside the interval $[\underline{\theta}, \bar{\theta}]$, the net balance between the flexibility effect and the efficiency effect becomes clear cut and independent of the level of $\Theta$.

The main results above are collected in the following proposition.

Proposition 2 Assume that capital mobility is imperfect and that tax revenue is not shared. Suppose integration improves the small jurisdiction's efficiency in public input provision.

(a) When the small jurisdiction's efficiency is originally sufficiently high (low), regional integration always reduces (improves) its net revenue, regardless of the extent of efficiency improvement. However,

(b) when the small jurisdiction's efficiency is originally intermediate, the impacts on net revenue crucially depend on the extent to which efficiency is improved. If integration improves the jurisdiction's efficiency significantly (moderately), the positive efficiency effect dominates (is dominated by) the negative flexibility effect and the jurisdiction's net revenue will be higher (lower) than under separation.

We illustrate the above results with the following figure.

Figure 1 is drawn in the $(\theta, \Theta)$-space. The arrows indicates how the small jurisdiction's net revenue changes for various combinations of pre-integration and post-integration levels of public sector efficiency. In area A of Figure 1, for example, the net revenue of the small jurisdiction decreases since integration reduces its public sector efficiency. In area $\mathrm{B}$ (E), net revenue always decreases (increases), independently of the efficiency improvement. However, in areas $\mathrm{C}$ and $\mathrm{D}$, the impacts of integration on net revenue crucially depend on the magnitude of efficiency improvement. In area $\mathrm{C}(\mathrm{D})$, net revenue decreases (increases) since the flexibility effect dominates (is dominated by) the efficiency effect. 


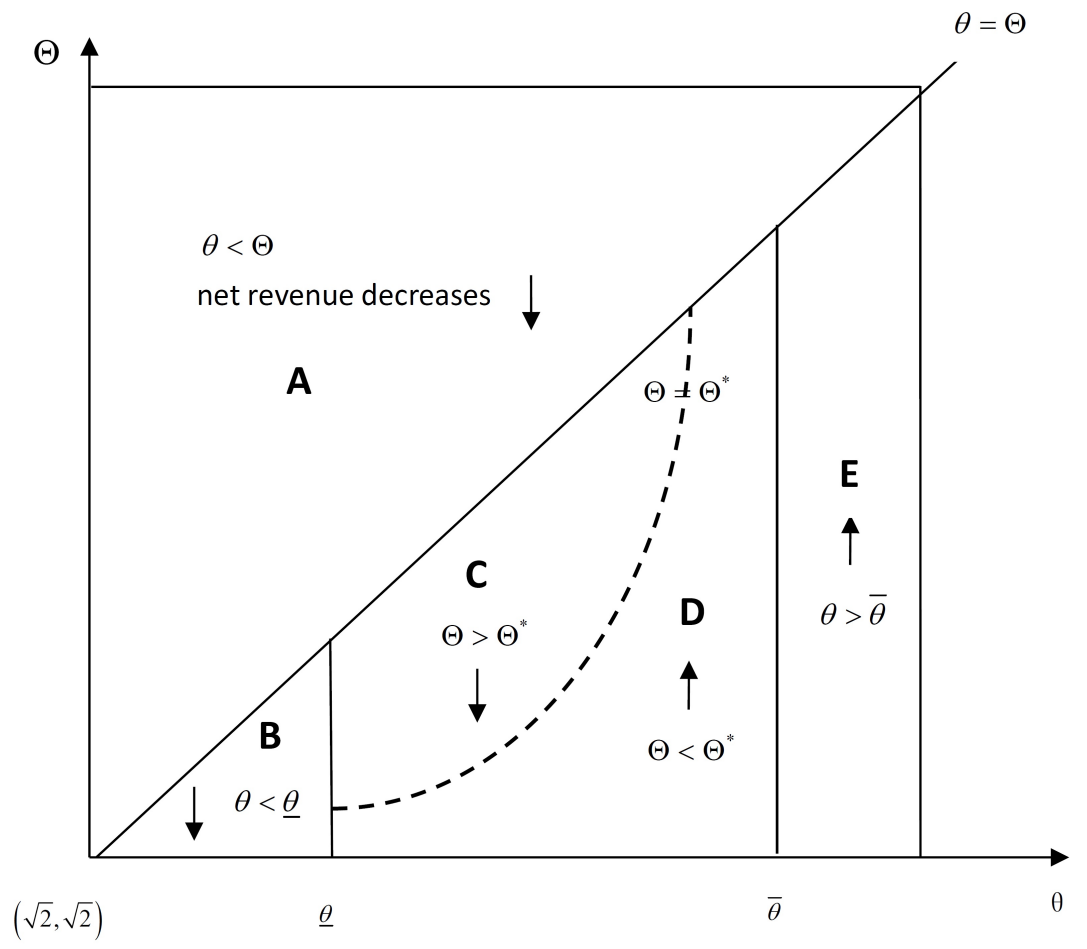

Figure 1: Public sector efficiency change and net revenue

\subsection{Flexibility vs. Factor Mobility}

As discussed above, integrating into the large jurisdiction will likely facilitate the mobility of capital, so per unit relocation cost of capital is lower under integration than under separation $(\Gamma<\gamma)$. In what follows, we investigate how this effect impacts the small jurisdiction's net revenue. For this purpose, we keep the public sector efficiency parameter constant $(\theta=\Theta)$ and assume away tax sharing $(\alpha=0)$.

First, we note that $\partial R^{I}(\theta, \Gamma, 0) / \partial \Gamma$ is always positive for $\theta>1 .^{23}$ In other words, under regional integration the net revenue of the small jurisdiction decreases with capital mobility. The intuition is that when capital mobility is high, competition for capital becomes fierce,

\footnotetext{
${ }^{23}$ This is because $\partial R^{I}(\theta, \Gamma, 0) / \partial \Gamma=\frac{1}{8 \theta \Gamma^{2}+8 r \theta \Gamma^{2}}(2 \theta+2 \theta \Gamma \sqrt{\Gamma(r+1)}+2 r \theta \Gamma \sqrt{\Gamma(r+1)}-1)$, which is positive for $\theta>1$.
} 
and this drives down tax rates and pushes up public input spending. Hence, with a higher degree of capital mobility, net revenue shrinks.

Recall that the flexibility effect is always negative in terms of the small jurisdiction's net revenue, other things being equal. Therefore, together with the negative capital mobility effect, the small jurisdiction's net revenue decreases if it integrates into the large jurisdiction.

Thus, we have the following proposition.

Proposition 3 Assume that the small jurisdiction's public sector efficiency does not change upon integration and that there is no tax sharing. Then, integration always reduces the net revenue of the small jurisdiction.

\subsection{Flexibility vs. Fiscal Equalization}

Next, we analyze how fiscal equalization affects the comparison of net revenues of the small jurisdiction under integration and under separation. To this end, we hold both the efficiency parameter and the unit relocation cost at their original levels under separation, $\theta$ and $\gamma$, respectively.

It can be verified that $\partial R^{I}(\theta, \gamma, \alpha) / \partial \alpha>0$ for $\alpha \in(0,1 / 2) \cdot{ }^{24}$ That is, the net revenue of the small jurisdiction increases with the degree of tax sharing $\alpha$ since the large jurisdiction has a larger tax base and hence higher tax revenue than the small one.

It can also be verified that $R^{s}(\theta, \gamma)-R^{I}(\theta, \gamma, \alpha)$ is decreasing in $\alpha .{ }^{25}$ Next, note that the minimum value of $R^{I}(\theta, \gamma, \alpha)$ is $R^{I}(\theta, \gamma, 0)=(1 / \theta-2) /[8 \gamma(r+1)]+\sqrt{\gamma(r+1)} / 2$ and its maximum value $R^{I}(\theta, \gamma, 1 / 2)$ approaches infinity as $\alpha$ tends to $1 / 2$. We see that $R^{s}(\theta, \gamma)-R^{I}(\theta, \gamma, \alpha)$ is positive for $\alpha=0$ and that $R^{s}(\theta, \gamma)-R^{I}(\theta, \gamma, \alpha)$ is negative as $\alpha$ goes to $1 / 2$. Hence, there exists a unique solution, $\alpha=\alpha^{*}(\theta, r, \gamma)$, to the equation

\footnotetext{
${ }^{24}$ To see this, note that $\partial R^{I}(\theta, \gamma, \alpha) / \partial \alpha=\frac{1}{8 \theta \gamma(r+1)}(12 \alpha+8 \theta-16 \alpha \theta-5)+\frac{\gamma}{4(2 \alpha-1)^{2}} \frac{r+1}{\sqrt{\gamma \frac{\alpha-1}{2 \alpha-1}(r+1)}}$. The first term is decreasing in $\alpha$ and tends to $1 / 2$ from below. The second term is positive. Therefore, $\partial R^{I}(\theta, \gamma, \alpha) / \partial \alpha>0$ for $\alpha \in(0,1 / 2)$.

${ }^{25}$ We have shown above that $\partial R^{I}(\theta, \gamma, \alpha) / \partial \alpha>0$ for $\alpha \in(0,1 / 2)$ and $R^{s}(\theta, \gamma)$ is independent of $\alpha$. Thus, it is obvious that $\frac{\partial}{\partial \alpha}\left(R^{s}(\theta, \gamma)-R^{I}(\theta, \gamma, \alpha)\right)<0$.
} 
$R^{s}(\theta, \gamma)-R^{I}(\theta, \gamma, \alpha)=0$, with the related property

$$
R^{s}(\theta, \gamma)-R^{I}(\theta, \gamma, \alpha) \gtreqless 0 \text { as } \alpha^{*} \gtreqless \alpha .
$$

From (7), we immediately see that, if $\alpha^{*}(\theta, r, \gamma)<\alpha<1 / 2$, then $R^{s}(\theta, \gamma)<R^{I}(\theta, \gamma, \alpha)$. When the extent of tax revenue sharing is higher than the threshold level $\alpha^{*}$, the positive fiscal equalization effect outweighs the negative flexibility effect. So integrating into the large jurisdiction increases the small jurisdiction's net revenue. On the other hand, if $\alpha<\alpha^{*}(\theta, r, \gamma)$, we get $R^{s}(\theta, \gamma)>R^{I}(\theta, \gamma, \alpha)$. In this case, the fiscal equalization effect does not compensate the negative impact on revenue that results from lower policy-making flexibility.

The above results can be summarized by the following proposition

Proposition 4 Fix public sector efficiency and factor mobility at their levels under separation and consider the effects of fiscal equalization. Integrating into the large jurisdiction improves the small jurisdiction's net revenue if the extent of tax sharing is high; otherwise, its net revenue decreases.

The results obtained above imply that the overall impact of integration on net revenue may be positive or negative. The flexibility effect and the capital mobility effect lower net revenue, while the fiscal equalization effect impacts net revenue positively and the efficiency effect may increase or decrease it. The overall impact on net revenue will therefore depend on which of these effects dominates.

As discussed earlier, convergence in economic outcomes among regions within a country or a union is of considerable recent interest including in the EU where regional policy, also referred to as cohesion policy, involves major investment aimed at strengthening economic and social cohesion and reducing disparities in the level of development among countries and regions. ${ }^{26}$ The policy is implemented through three main funds, which are often called 'Structural Funds'. These are the European Regional Development Fund, the Cohesion Fund, and the European Social Fund. Almost a third of the total EU budget has been set

\footnotetext{
${ }^{26} \mathrm{EU}$ Regional Policy webpage at http://ec.europa.eu/regional_policy/en/policy/what/ investment-policy/, accessed May 7, 2016 and July 23, 2017. Armstrong and Taylor (2000), chapter 11 .
} 
aside for cohesion policy for the period from 2014 to 2020. In what follows, we investigate an aspect of the convergence issue within the framework of our model. Specifically, we consider the impacts of regional integration on the small jurisdiction's GDP per capita.

\section{GDP Per Capita}

We continue to assume that the governments maximize tax revenues net of the costs of public inputs. Therefore, the analysis in this section will still be based on the steady state characterized in Section 4. From the entrepreneur's production function, we know that, in the steady state, the GDP per capita ${ }^{27}$ in the small jurisdiction under separation is

$$
G^{s}(\theta, \gamma)=\frac{K^{s} *\left(q+g_{1}^{s}\right)}{K^{s}}=q+g_{1}^{s} .
$$

and the GDP per capita under integration is

$$
G^{I}(\Theta, \Gamma, \alpha)=\frac{K^{I} *\left(q+g_{1}^{I}\right)}{K^{I}}=q+g_{1}^{I},
$$

Thus, from the expressions of $g_{1}^{s}$ and $g_{1}^{I}$ in (2) and (4), the difference between the two levels of GDP per capita is given by

$$
\begin{aligned}
& G^{s}(\theta, \gamma)-G^{I}(\Theta, \Gamma, \alpha) \\
= & g_{1}^{s}-g_{1}^{I} \\
= & \frac{1}{2 \theta \sqrt{\gamma(r+1)}}-\frac{1}{\Theta} \frac{\sqrt{2 \alpha^{2}-3 \alpha+1}}{2 \sqrt{\Gamma(r+1)}} .
\end{aligned}
$$

Note that, if public sector efficiency and relocation cost do not change upon integration $(\Theta=\theta$ and $\Gamma=\gamma)$ and there is no equalization $(\alpha=0)$, the small jurisdiction's steady state public input spending will be the same whether it integrates or stays outside $\left(g_{1}^{I}=g_{1}^{s}\right)$, so its GDP levels will also be the same. This has the interesting implication that, under the conditions listed above, the change in flexibility due to integration in fact does not

\footnotetext{
${ }^{27}$ Han et al. (2014) suggests that, at steady state, GDP per capita increases with the inflow of FDI. The focus of the present paper is completely different: The tradeoffs between flexibility loss and the three integration effects are analyzed by comparing the GDP per capita under integration with that under separation.
} 
affect the small jurisdiction's optimal choice of public input. This is a result of the special structure of the jurisdictions' optimization problems, and its intuitive reason is as follows. We know that the large jurisdiction always plays open-loop strategies under both integration and separation. Thus, under the conditions above, the small jurisdiction essentially faces the same situation under both regimes. The first-order conditions governing the small jurisdiction's tax and public input choices and its costate equation have the same expressions across regimes. On the other hand, because the small jurisdiction plays open-loop strategy under integration but Markovian strategy under separation, the large jurisdiction faces different situations across regimes and therefore have different first-order conditions and costate equations. Thus, although it is the small jurisdiction that changes the type of strategy it plays across regimes, it is the change in the optimal responses by the large jurisdiction that brings the differences in equilibrium outcomes, including, in particular, the equilibrium capital stock in each jurisdiction. Due to the separability between tax $T_{i}$ and public input $g_{i}$ in the objective functions, the optimal policies have the property that equilibrium capital stock in each jurisdiction enters the expressions for taxes $T_{i}$ but not those for public inputs $g_{i}$. Hence, under the conditions stated above, the small jurisdiction's steady state public input levels are the same across regimes. Of course, when not all the restrictive conditions listed above hold (i.e., efficiency or relocation cost changes, or there is equalization), the small jurisdiction's public input choice and hence GDP will differ across regimes. Below, we focus on such a situation and briefly consider the other effects. We start with the efficiency effect.

Efficiency To focus on the efficiency effect on the small jurisdiction's GDP per capita, we assume that there is no fiscal equalization $(\alpha=0)$ and that integration does not change the relocation cost parameter $\gamma$. Then, $G^{s}(\theta, \gamma)-G^{I}(\Theta, \Gamma, \alpha)$ in (8) becomes

$$
\frac{1}{2 \theta \sqrt{\gamma(r+1)}}-\frac{1}{2 \Theta \sqrt{\gamma(r+1)}}
$$

Thus, the impacts of regional integration on the small jurisdiction's GDP per capita crucially depends on how the efficiency of public input provision changes. There can be two cases.

In the first case, joining the large jurisdiction reduces the efficiency of public spending $(\Theta>\theta)$. In this case, the efficiency effect on GDP per capita is negative. Intuitively, the 
more costly are public infrastructure investments, the less the small jurisdiction will provide them. As a result, GDP per capita in the small jurisdiction is lower under integration, $G^{s}(\theta, \gamma)>G^{I}(\Theta, \Gamma, \alpha)$

In the second case, integration improves efficiency of public input provision $(\Theta<\theta)$, so the efficiency effect is positive and GDP per capita is higher under integration, $G^{s}(\theta, \gamma)<$ $G^{I}(\Theta, \Gamma, \alpha)$.

Factor Mobility As discussed in the model setup section, it is reasonable to assume that integrating into the large jurisdiction generates a higher degree of capital mobility, that is, $\Gamma<\gamma$. In the following, we investigate how this mobility effect impacts the small jurisdiction's GDP per capita, holding constant the efficiency parameter $\theta$ and abstracting from fiscal equalization $(\alpha=0)$.

It is easy to check that $\partial G^{I}(\theta, \Gamma, \alpha) / \partial \Gamma<0$. That is, a higher degree of capital mobility induces a higher level of GDP per capita in the small jurisdiction if it joins the large jurisdiction.

Therefore, increased capital mobility has a positive impact on GDP per capita. When capital is highly mobile, competing jurisdictions have to invest more in public input in order to attract capital. Higher public input provision increases the output of the firms. Hence, integrating into the large jurisdiction increases GDP per capita, $G^{s}(\theta, \gamma)<G^{I}(\theta, \Gamma, \alpha)$, as long as capital mobility is enhanced $(\Gamma<\gamma)$.

Fiscal Equalization To study the tax sharing effect, we hold constant the efficiency parameter $\theta$ and the relocation cost parameter $\gamma$. From the expression of $g_{1}^{I}$, we see that, for $\alpha \in(0,1 / 2), \partial G^{I}(\theta, \gamma, \alpha) / \partial \alpha$ is always negative. That is, the tax sharing policy always negatively affects the small jurisdiction's GDP per capita. This negative effect comes from the fact that, with a tax sharing scheme, the competing jurisdictions have weaker incentives to attract capital and collect tax revenue than without such a policy. Therefore, GDP per capita is always lower under integration, $G^{s}(\theta, \gamma)>G^{I}(\theta, \gamma, \alpha)$, for all $\alpha \in(0,1 / 2)$.

We summarize the findings of this section in the following proposition

Proposition 5 Integration increases (decreases) the small jurisdiction's GDP per capita if 
its efficiency is improved (worsened). Enhanced capital mobility increases GDP per capita of the small jurisdiction, while fiscal equalization reduces it.

Finally, just as in the case of net revenue, the overall impact of integration on GDP per capita may be positive or negative. Recall that the flexibility effect is neutral. The capital mobility effect is positive, while the fiscal equalization effect is negative. Moreover, the efficiency effect may be positive or negative. The combined impact will therefore depend on which of these effects dominates.

\section{Conclusions}

In this paper, we have investigated the economic impacts of regional integration on a small jurisdiction from the net fiscal revenue and the GDP per capita perspectives. These impacts are analyzed by considering the tradeoffs between the economic benefits and costs in a dynamic fiscal competition context. Compared with the existing literature, we introduce the loss of policy flexibility for the small, integrating jurisdiction as a new cost of integration.

We employ a differential game framework to model the dynamic inter-jurisdictional competition. More precisely, two regimes are developed to capture the impact of integration on the small jurisdiction's policy-making flexibility. Under separation, we assume that the small jurisdiction is able to adjust its policies based on the current state and hence plays a Markovian strategy, while its large competitor plays an open-loop strategy. Under integration, the small jurisdiction loses flexibility in decision making, and we assume that both rivals play open-loop strategies. The competing jurisdictions are assumed to maximize net fiscal revenue by choosing tax rates and the provisions of public inputs.

From the fiscal revenue perspective, if regional integration reduces public sector efficiency of the small jurisdiction, regional integration can be beneficial only when the gains from fiscal equalization outweighs the losses from the flexibility effect, the efficiency effect and the capital mobility effect. However, if integration improves public sector efficiency, the small jurisdiction's net revenue increases when the positive efficiency effect and fiscal equalization effect dominate the negative flexibility effect and capital mobility effect. 
From the GDP per capita perspective, if regional integration reduces the public sector efficiency of the small jurisdiction, the small jurisdiction's GDP per capita can improve only when the capital mobility effect compensates for the loss from the efficiency effect and the fiscal equalization effect. On the other hand, if integration improves public sector efficiency, the small jurisdiction's GDP per capita will increase if the positive efficiency effect and capital mobility effect dominate the negative fiscal equalization effect.

In practice, whether a small jurisdiction should join a large one is a difficult and complicated question. The literature has fruitfully identified a number of important factors that should be considered. For example, on the benefit side of integration, there are economies in public service provision and better trade and growth potentials. On the cost side, a frequent focus has been the economic and political costs of population heterogeneity. Following the literature, we have focused on similar benefits, but we have explored a new type of cost - the loss of flexibility in policy making - in a genuinely dynamic framework. Our analysis reveals that flexibility considerations can alter various benefit-cost comparisons and can therefore be important. For example, taking a net revenue / Leviathan government perspective, we saw that a jurisdiction is more likely to prefer integration if its public sector efficiency is initially low or is intermediate but can improve a lot after joining, if it is poorer than the other jurisdiction and can thus get significant fiscal transfers after integration, or if integration does not increase capital mobility much. All these conditions are more likely to hold for smaller jurisdictions than for larger ones. However, smaller jurisdictions are also the more flexible ones. Thus, upon integration, they are more likely to suffer from the loss of policy-making flexibility.

Our analysis could be extended in various directions. In our dynamic setting, we have assumed that the small jurisdiction plays open-loop strategy under integration, which means that its policy path is decided at the beginning of the game. However, if the small jurisdiction can choose the time to integrate (e.g., when to join the EU?), it could be the case that the small jurisdiction plays Markovian strategy at the beginning of the game and changes to open-loop strategy after it integrates with the large jurisdiction. It may be interesting to consider the optimal timing of regime switch, as for example Boucekkine et al. (2013) did in the context of capital controls. In the context of our model, it may also be interesting to characterize how integration affects the large jurisdiction's net revenue and GDP per capita. Doing so may provide insights about the conditions, with respect 
to capital mobility and fiscal equalization for example, under which the large jurisdiction would support integration. That may help us understand issues of regional integration that are broader than those studied in the present paper. Finally, it may be worthwhile trying to introduce the issue of flexibility changes into models of political decision making. In the model of this paper, flexibility loss is treated as exogenous and simply modeled as a switch from Markovian strategies to open-loop strategies. The changes in the political decision processes that actually cause the flexibility loss are not explicitly modeled. It may be interesting to build a political economy model that can be used to study the changes in flexibility. 


\section{References}

[1] Alesina A. and E.L. Ferrara, 2005. Ethnic diversity and economic performance. Journal of Economic Literature, Vol. 43(3), 762-800.

[2] Alesina A. and E. Spolaore, 1997. On the number and size of nations. Quarterly Journal of Economics 112, 1027-56.

[3] Alesina A. and E. Spolaore, 2003. The Size of Nations, MIT Press, Cambridge, MA.

[4] Alesina A. and R. Wacziarg, 1998. Openness, country size and government. Journal of Public Economics 69, 305-321.

[5] Alesina A., I. Angeloni, and F. Etro, 2005. International unions. The American Economic Review 95(3), 602-615.

[6] Alesina A., E. Spolaore, and R. Wacziarg, 2000. Economic integration and political disintegration. American Economic Review 90(5),1276-1296.

[7] Anderson J.A. and E. van Wincoop, 2003. Gravity with gravitas: A solution to the border puzzle. American Economic Review 93, 170-192.

[8] Aviat A. and N. Coeurdacier, 2007. The geography of trade in goods and asset holdings. Journal of International Economics 71(1), 22-51.

[9] Badinger H., 2005. Growth effects of economic integration: Evidence from the EU Member States. Review of World Economics 141, 50-78.

[10] Becker S.O., P.H. Egger, and M. von Ehrlich, 2010. Going NUTS: The effect of EU Structural Funds on regional performance. Journal of Public Economics 94, 578-590.

[11] Blumenthal M. and J. Slemrod, 1992. The compliance cost of the U.S. individual tax system: a second look after tax reform. National Tax Journal 45(2), 186-202.

[12] Boadway R., 2007. Grants in a federal economy: A conceptual perspective. In: Boadway, R. and Shah, A. (eds.), Intergovernmental Fiscal Transfers: Principles and Practice, The World Bank, Washington, pp. 55-74 (Ch. 2). 
[13] Boadway R. and A. Shah (eds.), 2007. Intergovernmental Fiscal Transfers: Principles and Practice. The World Bank, Washington.

[14] Boadway R. and A. Shah, 2009. Fiscal Federalism: Principles and Practices of Multiorder Governance. Cambridge University Press, New York.

[15] Bolton P. and G. Roland, 1996. Distribution conflicts, factor mobility and political integration. American Economic Review 86, 99-104.

[16] Bolton P. and G. Roland, 1997. The breakup of nations: a political economy analysis. The Quarterly Journal of Economics, Vol. 112 (4), 1057-1090.

[17] Bolton P., G. Roland and Spolaore E., 1996. Economic theories of the break-Up and integration of nations. European Economic Review, 40(3-5), 697-705.

[18] Bordignon M., P. Manasse and G. Tabellini, 2001. Optimal regional redistribution under asymmetric information. The American Economic Review 91 (3), 709-723.

[19] Boucekkine R., A. Pommeret and F. Prieur, 2013. On the timing and optimality of capital controls: Public expenditures, debt dynamics and welfare. International Journal of Economic Theory 9(1), 101-112.

[20] Bucovetsky S. and M. Smart, 2006. The efficiency consequences of local revenue equalization: Tax competition an tax distortions. Journal of Public Economic Theory 8, 119-144.

[21] Campos N.F., F. Coricelli and L. Moretti, 2014. Economic growth and political integration: Estimating the benefits from membership in the European Union using the synthetic counterfactuals method. IZA DP No. 8162.

[22] Casella A. and J.S. Feinstein, 2002. Public goods in trade: on the formation of markets and politicalInstitutions. International Economic Review 43, 437-62.

[23] Coates D., 1993. Property tax competition in a repeated game. Regional Science and Urban Economics 23, 111-119.

[24] Commonwealth Secretariat, 2000. Small states: Meeting challeges in the global economy, Report of the Commonwealth Secretariat/ World Bank Joint Task Force on Small States. 
[25] Desmet K., M. Breton, I. Ortuno-Ortin and S. Weber, 2011. The stability and breakup of nations: a quantitive analysis. Journal of Economic Growth 16, 183-213.

[26] Edwards J. and M. Keen, 1996. Tax competition and Leviathan. European Economic Review 40(1), 113-134.

[27] Gong L. and H. Zou, 2002. Optimal taxation and intergovernmental transfer in a dynamic model with multiple levels of government. Journal of Economic Dynamics and Control 26 (12), 1975-2003.

[28] Han Y., P. Pieretti, S. Zanaj and B. Zou, 2014. Asymmetric competition among nation states: a differential game approach. Journal of Public Economics 119, 71-79.

[29] Hauptmeier S., F. Minttermaier and J. Rincke, 2012. Fiscal competition over taxes and public inputs. Regional Science and Urban Economics 42, 407-419.

[30] Henrekson M., J. Torstensson and R. Torstensson, 1997. Growth effects of european integration. European Economic Review 41, 1537-1557.

[31] Hindriks J, S. Peralta and S. Weber, 2008. Competing in taxes and investment under fiscal equalization. Journal of Public Economics 92, 2392-2402.

[32] Kato H., 2015. The importance of government commitment in attracting firms: A dynamic analysis of tax competition in an agglomeration economy. European Economic Review 74, 57-78.

[33] Keen M. and C. Kotsogiannis, 2003. Leviathan and capital tax competition in federations. Journal of Public Economic Theory 5(2), 177-199.

[34] Keen M. and M. Marchand, 1997. Fiscal competition and the pattern of public spending. Journal of Public Economics 66, 33-53.

[35] Kenny L. and S. Winer, 2006. Tax systems in the world: An empirical investigation into the importance of tax bases, administration costs, scale and political regime. International Tax and Public Financ 13(2), 181-215.

[36] Kuznets S., 1960. Economic growth of small nations. In: Robinson, E.A.G. (ed.), The Economic Consequences of the Size of Nations: Proceedings of a Conference Held by the International Economic Associations, MacMillan, Toronto. 
[37] Mansoorian A., G.M. Myers, 1993. Attachment to home and efficient purchases of population in a fiscal externality economy. Journal of Public Economics 52, 117-132.

[38] Martin P., T. Mayer and M. Thoenig, 2012. The geography of conflicts and regional trade agreements. American Economic Journal: Macroeconomics 4(4), 1-35.

[39] McCallum J., 1995. National borders matter: Canada-U.S. regional trade patterns. The American Economic Review 85(3), 615-623.

[40] Mohl P. and T. Hagen, 2010. Do EU structural funds promote regional growth? New evidence from various panel data approaches. Regional Science and Urban Economics 40, 353-365.

[41] Oates W., 1972. Fiscal Federalism. New York: Harcourt Brace Jovanovich.

[42] Pieretti P. and S. Zanaj, 2011. On tax competition, public goods provision and jurisdictions' size. Journal of International Economics 84(1), 124-130.

[43] Portes R. and H. Rey, 2005. The determinants of cross-border equity flows. Journal of International Economics 65(2), 269-296.

[44] Ramajoa J., M.A. Márquez, G.J.D. Hewings, and M.M. Salinas, 2008. Spatial heterogeneity and interregional spillovers in the European Union: Do cohesion policies encourage convergence across regions? European Economic Review 52, 551-567.

[45] Rodrik D., 1998. Why do more open economies have bigger governments? Journal of Political Economy 106, 997-1032.

[46] Ruta M., 2005. Economic theories of political (dis)integration. Journal of Economic Surveys 19 (1), 1-21.

[47] Sambanis, N., 2006. Globalization, decentralization, and secession: A review of the literature and some conjectures. In: G. Ranis, D. Cameron and A. Zinn (Eds.), Globalization and Self-Determination: Is the Nation-State under Siege? New York: Routledge.

[48] Sorens J., 2005. The cross-sectional determinants of secessionism in advanced democracies. Comparative Political Studies 38, 304-326. 
[49] Streeten P., 1993. The special problems of small countries. World Development 21(2), 197-202.

[50] Vaillancourt F., 1989. The administrative and compliance costs of the personal income tax and payroll tax system in Canada. Canadian Tax Papers, No. 86. Canadian Tax Foundation (c1989).

[51] Von Hagen J., 2007. Achieving economic stabilization by sharing risk within countries. In: Boadway, R. and Shah, A. (eds.), Intergovernmental Fiscal Transfers: Principles and Practice, The World Bank, Washington, pp. 107-132 (Ch. 4).

[52] Wagner H., 2006. Fiscal issues in the new EU member countries: Prospects and challenges. SUERF Studies, 2006/1. SUERF, Vienna.

[53] Wildasin D.E., 2003. Fiscal competition in space and time. Journal of Public Economics $87,2571-2588$.

[54] Wildasin D.E., 2011. Fiscal competition for imperfectly-mobile labor and capital: a comparative dynamic analysis. Journal of Public Economics 95, 1312-1321.

[55] Wrede M., 1996. Vertical and horizontal tax competition: Will unco-ordinated leviathans end up on the wrong side of the Laffer curve? FinanzArchiv / Public Finance Analysis 53, 461-479.

[56] Zissimos B. and M. Wooders, 2008. Public good differentiation and the intensity of tax competition. Journal of Public Economics 92, 1105-1121. 


\section{A Appendix}

\section{A.1 The Steady State under Separation}

When the small jurisdiction stays outside the large jurisdiction, it is able to adjust its

policies depending on the current state. We assume the small jurisdiction plays Markovian strategy while its large rival plays open-loop strategy.

The small jurisdiction's problem is

$$
\max _{g_{1}(K, t), T_{1}(K, t)} \int_{0}^{\infty} e^{-r t}\left(\sqrt{K T_{1}(K, t)}-\frac{\theta}{2} g_{1}^{2}(K, t)\right) d t
$$

subject to

$$
\dot{K(t)}=\frac{\left(g_{1}(K, t)-T_{1}(K, t)\right)-\left(g_{2}(t)-T_{2}(t)\right)}{\gamma}-(K(t)-K(0)) .
$$

The large jurisdiction's problem is

$$
\max _{g_{2}(t), T_{2}(t)} \int_{0}^{\infty} e^{-r t}\left(\sqrt{(1-K) T_{2}(t)}-\frac{1}{2} g_{2}^{2}(t)\right) d t
$$

subject to (9) as well.

Therefore, the respective Hamiltonian functions of the small and large jurisdictions are given by

$$
\begin{aligned}
& \mathcal{H}_{1}\left(g_{1}(K, t), T_{1}(K, t), K, \lambda_{1}(t)\right)=\left(\sqrt{K T_{1}(K, t)}-\frac{\theta}{2} g_{1}^{2}(K, t)\right) \\
& +\lambda_{1}(t)\left[\frac{\left(g_{1}(K, t)-T_{1}(K, t)\right)-\left(g_{2}(t)-T_{2}(t)\right)}{\gamma}-(K(t)-K(0))\right]
\end{aligned}
$$

and

$$
\begin{aligned}
& \mathcal{H}_{2}\left(g_{2}(t), T_{2}(t), K, \lambda_{2}(t)\right)=\left(\sqrt{(1-K) T_{2}(t)}-\frac{1}{2} g_{2}^{2}(t)\right) \\
& +\lambda_{2}(t)\left[\frac{\left(g_{1}(K, t)-T_{1}(K, t)\right)-\left(g_{2}(t)-T_{2}(t)\right)}{\gamma}-(K(t)-K(0))\right],
\end{aligned}
$$

where $\lambda_{1}$ and $\lambda_{2}$ are the costate variables of the small and large jurisdictions, respectively.

Thus, the first order conditions yield the following optimal conditions

$$
g_{1}(t)=\frac{\lambda_{1}(t)}{\theta \gamma}, \quad T_{1}(K, t)=\frac{\gamma^{2} K}{4 \lambda_{1}^{2}(t)}, \quad g_{2}(t)=-\frac{\lambda_{2}(t)}{\gamma}, \quad T_{2}(t)=\frac{\gamma^{2}(1-K)}{4 \lambda_{2}^{2}(t)},
$$


where the two costate variables check

$$
\begin{gathered}
\dot{\lambda_{1}}(t)=(r+1) \lambda_{1}(t)-\frac{\gamma}{4 \lambda_{1}(t)}, \\
\dot{\lambda_{2}}(t)=(r+1) \lambda_{2}(t)-\frac{\gamma}{4 \lambda_{2}(t)}+\frac{\gamma \lambda_{2}(t)}{4 \lambda_{1}^{2}(t)},
\end{gathered}
$$

and transversality conditions

$$
\lim _{t \rightarrow \infty} e^{-r t} \lambda_{1}(t) K(t)=0, \quad \lim _{t \rightarrow \infty} e^{-r t} \lambda_{2}(t)(1-K(t))=0
$$

It is easy to check that the above dynamic system contain one and only one steady state, which is given by

$$
\begin{gathered}
\lambda_{1}^{S}=\frac{1}{2} \sqrt{\frac{\gamma}{r+1}}, \quad \lambda_{2}^{S}=-\frac{1}{2} \sqrt{\frac{\gamma}{2(r+1)}} \\
K^{S}=\frac{\left(\frac{1}{\gamma(r+1)}\right)^{\frac{1}{2}} \frac{1}{2 \sqrt{2}}\left(\frac{\sqrt{2}}{\theta}-1\right)}{3 \gamma r+4 \gamma}+\frac{2 r+(2+K(0))}{3 r+4},
\end{gathered}
$$

and

$$
\begin{array}{ll}
g_{1}^{S}=\frac{1}{2 \theta \sqrt{\gamma(r+1)}}, \quad T_{1}^{S}=\gamma(r+1) K^{S} \\
g_{2}^{S}=\frac{1}{2 \sqrt{2 \gamma(r+1)}}, \quad T_{2}^{S}=2 \gamma(r+1)\left(1-K^{S}\right)
\end{array}
$$

Thus, it is straightforward to prove that the canonical system has three eigenvalues at the above steady state and are given by the following:

$$
\eta_{1}=-3 r-4<0, \quad \eta_{2}=2(r+1)>0, \quad \eta_{3}=3(r+1)>0
$$

The existence of one and only one negative eigenvalue implies that the dynamic system is locally asymptotic stable in its state space and the convergence speed is $3 r+4$. Hence, the convergent path is

$$
K(t)=\left(K(0)-K^{S}\right) e^{\eta_{1} t}+K^{S} .
$$




\section{A.2 The Steady State under Integration}

When the small jurisdiction joins the large jurisdiction, it has to commit to a policy path that is decided at the beginning of the game. Thus, we assume that both jurisdictions play open-loop strategy. In the following, we derive the Nash equilibrium of the differential game.

The small jurisdiction faces the following optimization problem:

$$
\left\{\begin{array}{l}
\max _{T_{1}(t), g_{1}(t)} \int_{0}^{\infty} e^{-r t}\left[(1-\alpha) \sqrt{K T_{1}}+\alpha \sqrt{(1-K) T_{2}}-\frac{\Theta}{2} g_{1}^{2}\right] d t, \\
\text { subject to } \dot{K}(t)=\frac{g_{1}(t)-T_{1}(t)}{\Gamma}-\frac{g_{2}(t)-T_{2}(t)}{\Gamma}-(K(t)-K(0)) .
\end{array}\right.
$$

The corresponding current-value Hamiltonian is

$$
\begin{gathered}
\mathcal{H}_{1}\left(T_{1}, K, g_{1}, \lambda_{1}\right)=\left[(1-\alpha) \sqrt{K T_{1}}+\alpha \sqrt{(1-K) T_{2}}-\frac{\Theta}{2} g_{1}^{2}\right] \\
+\lambda_{1}(t)\left[\frac{g_{1}(t)-T_{1}(t)}{\Gamma}-\frac{g_{2}(t)-T_{2}(t)}{\Gamma}-(K(t)-K(0))\right]
\end{gathered}
$$

where $\lambda_{1}(t)$ denotes a costate variable.

The large jurisdiction faces the following problem:

$$
\left\{\begin{array}{l}
\max _{g_{2}(t), T_{2}(t)} \int_{0}^{\infty} e^{-r t}\left[(1-\alpha) \sqrt{(1-K) T_{2}}+\alpha \sqrt{K T_{1}}-\frac{1}{2} g_{2}^{2}\right] d t, \\
\text { subject to } \dot{K}(t)=\frac{g_{1}(t)-T_{1}(t)}{\Gamma}-\frac{g_{2}(t)-T_{2}(t)}{\Gamma}-(K(t)-K(0)) .
\end{array}\right.
$$

Thus, the current-value Hamiltonian of the large economy is defined as

$$
\begin{gathered}
\mathcal{H}_{2}\left(T_{2}, K, g_{2}, \lambda_{2}\right)=\left[(1-\alpha) \sqrt{(1-K) T_{2}}+\alpha \sqrt{K T_{1}}-\frac{1}{2} g_{2}^{2}\right] \\
+\lambda_{2}(t)\left[\frac{g_{1}(t)-T_{1}(t)}{\Gamma}-\frac{g_{2}(t)-T_{2}(t)}{\Gamma}-(K(t)-K(0))\right]
\end{gathered}
$$

with $\lambda_{2}(t)$ its costate variable.

The first order conditions yield the small jurisdiction's equilibrium choices $T_{1}(t)=$ $\left(\frac{\Gamma(1-\alpha)}{2 \lambda_{1}}\right)^{2} K, g_{1}(K, t)=\frac{\lambda_{1}(t)}{\Gamma \Theta}$. The costate variable verifies the equation

$$
\dot{\lambda}_{1}=(r+1) \lambda_{1}-\frac{\Gamma(1-\alpha)^{2}}{4 \lambda_{1}}-\frac{\Gamma \alpha(1-\alpha)}{4 \lambda_{2}}
$$


with the transversality condition $\lim _{t \rightarrow \infty} e^{-r t} \lambda_{1}(t) K(t)=0$.

The optimal choices of the large jurisdiction are $g_{2}(t)=-\frac{\lambda_{2}(t)}{\Gamma}, T_{2}(t)=\left(\frac{\Gamma(1-\alpha)}{2 \lambda_{2}(t)}\right)^{2}(1-$ $K(t))$ with the costate equation

$$
\dot{\lambda}_{2}=(r+1) \lambda_{2}-\frac{\Gamma(1-\alpha)^{2}}{4 \lambda_{2}}-\frac{\Gamma \alpha(1-\alpha)}{4 \lambda_{1}} .
$$

The associated transversality condition is $\lim _{t \rightarrow \infty} e^{-r t} \lambda_{2}(t) K(t)=0$.

It is straightforward that the maximized Hamiltonian are concave with respect to the state variable $K$, hence, $g_{i}(t), T_{i}(t), i=1,2$, are optimal paths. Therefore, the solutions $\left(g_{1}(t), T_{1}(t)\right)$ and $\left(g_{1}(t), T_{2}(t)\right)$ for $K \in[0,1]$ and $t \geq 0$ are one pair of Nash Equilibrium strategies.

At the Nash equilibrium, there is a potential interior steady state

$$
\begin{array}{lll}
g_{1}^{I}=\frac{1}{\Theta} \frac{\sqrt{2 \alpha^{2}-3 \alpha+1}}{2 \sqrt{\Gamma(r+1)}}, & T_{1}^{I}=\frac{\Gamma(r+1)(1-\alpha)}{1-2 \alpha} K^{I}, \\
g_{2}^{I}=\frac{\sqrt{2 \alpha^{2}-3 \alpha+1}}{2 \sqrt{\Gamma(r+1)}}, & T_{2}^{I}=\frac{\Gamma(r+1)(1-\alpha)}{1-2 \alpha}\left(1-K^{I}\right) .
\end{array}
$$

The small jurisdiction's capital stock in the steady state is

$$
K^{I}=\frac{\left(2 \alpha^{2}-3 \alpha+1\right)^{\frac{3}{2}}}{4(\Gamma(r+1))^{\frac{3}{2}}(1-\alpha)^{2}}\left(\frac{1}{\Theta}-1\right)+\frac{1}{2}
$$

with the costate variables

$$
\begin{aligned}
\lambda_{1}^{I} & =\frac{\sqrt{2 \Gamma \alpha^{2}-3 \Gamma \alpha+\Gamma}}{2 \sqrt{r+1}}, \\
\lambda_{2}^{I} & =-\frac{\sqrt{2 \Gamma \alpha^{2}-3 \Gamma \alpha+\Gamma}}{2 \sqrt{r+1}} .
\end{aligned}
$$

Notice that The steady state is a saddle point of the canonical system and that it is one dimensional locally asymptotically stable. 